\title{
Preparation of New Composite Films Composed of Size-Controlled Cobalt Oxide Nanoparticles Dispersed in Organically Modified Silica Glass
}

\author{
Pierre Audebert ${ }^{*}, 1$, Masanori Ando ${ }^{*, 2}$ and Koji Tanaka ${ }^{3}$
}

\author{
${ }^{1}$ Laboratoire de Photophysique et Photochimie Supramoléculaires et Macromoléculaires (PPSM), École Normale \\ Supérieure de Cachan, 61 avenue du Président Wilson, 94235 Cachan Cédex, France \\ ${ }^{2}$ Health Research Institute, National Institute of Advanced Industrial Science and Technology (AIST), Kansai Center, 1- \\ 8-31 Midorigaoka, Ikeda, Osaka 563-8577, Japan \\ ${ }^{3}$ Research Institute for Ubiquitous Energy Devices, National Institute of Advanced Industrial Science and Technology \\ (AIST), Kansai Center, 1-8-31 Midorigaoka, Ikeda, Osaka 563-8577, Japan
}

\begin{abstract}
The pyrolysis of transition metal carboxylates into organically modified silica glass- $\mathrm{ZrO}_{2}$ hybrid sol-gel films yields composite materials containing cobalt oxide nanoparticles in various proportions. The particles have sizes ranging from 5 to $10 \mathrm{~nm}$, and they are homogeneously dispersed in the final materials. A reaction temperature near $250^{\circ} \mathrm{C}$ results in translucent films that have good mechanical properties and that could find application in nonlinear optics.
\end{abstract}

Keywords: Nanoparticles, cobalt oxide, hybrid sol-gel films.

\section{INTRODUCTION}

Materials containing cobalt oxide nanoparticles are interesting in relation with their potential applications in novel high-performance nonlinear optical devices $[1,2]$ and chemical sensors [3-6]. $\mathrm{Co}_{3} \mathrm{O}_{4}$ films prepared by a metal saltpyrolysis method [3] (pyrolysis of spin-coated films of Co octanoate, which at temperatures above $350^{\circ} \mathrm{C}$ decomposes into oxide, through a variant of the Piria reaction [7]) have considerably large third-order optical nonlinearities [1]. The large third-order nonlinear susceptibility $\left(\chi^{(3)}\right)$ of these films suggests that they would be useful in optical switching and optical limiting applications. $\mathrm{Co}_{3} \mathrm{O}_{4}$ nanoparticles have been made by hydrolytic [8-10], mechanochemical [11] and pyrolytic [12] methods, but there have been no attempts to prepare glasses coatings embedded with cobalt oxide nanoparticles. This is surprising because the mechanical resistance of such coatings makes them easier to handle than nanoparticle powder (which for many applications needs to be processed in a polymer or some other binder).

The sol-gel technique of polymerization of various alkoxides is known to be advantageous for preparing oxide materials in various shapes and sizes that meet optical transparency requirements. Glasses with very good optical quality have been prepared through thermal treatment of hybrid xerogels.

\footnotetext{
*Address correspondence to these authors at the Laboratoire de Photophysique et Photochimie Supramoléculaires et Macromoléculaires (PPSM), École Normale Supérieure de Cachan, 61 avenue du Président Wilson, 94235 Cachan Cédex, France; Tel: +33 (0)1 474053 13; Fax: +33 (0)1 474024 54; E-mail: audebert@ppsm.ens-cachan.fr

Health Research Institute, National Institute of Advanced Industrial Science and Technology (AIST), Kansai Center, 1-8-31 Midorigaoka, Ikeda, Osaka 563-8577, Japan; Tel: (+81)-72-751-8489; Fax: (+81)-72-751-9637;

E-mail:m-ando@aist.go.jp
}

$\mathrm{Co}_{3} \mathrm{O}_{4}$ particles dispersed in transparent glass are especially interesting from the viewpoint of nonlinear optical applications because $\mathrm{Co}_{3} \mathrm{O}_{4}$ has a large $\chi^{(3)}$ and large figure of merit $\left(\chi^{(3)} / \alpha\right.$, where $\alpha$ is the linear absorption coefficient of the material). Furthermore, by combining $\mathrm{Co}_{3} \mathrm{O}_{4}$ particles (refractive index $n=1.71$ ) with silica glass with a smaller $n$ (e.g., 1.457), we can reduce the light scattering at the surface of the material. We can therefore expect to increase the 3rdorder nonlinear optical effect by introducing intense incident light through the low-reflection surface of silica glass containing highly dispersed $\mathrm{Co}_{3} \mathrm{O}_{4}$ particles.

Here we show how sol-gel hybrid/metal oxide nanoparticles composites can be made by first making homogeneous xerogels incorporating cobalt octanoate and then subjecting the xerogels to a thermal treatment that converts the xerogel into a hybrid glass and produces embedded oxide nanoparticles by pyrolysis of the metal octanoate.

From the chemical point of view, the sol-gel method has another remarkable advantage for preparing highly dispersed nonlinear optical metal oxide particles in a glass matrix when it is combined with metal salt-pyrolysis method because the diffusion coefficient in the xerogel is more than 1000 times smaller than in the melt octanoate. This large difference in diffusion coefficients helps in reducing the size of the particles by suppressing the formation of large oxide particles, since aggregation is a diffusion-limited process and the movement and diffusion of the metal octanoate are very slow in the xerogel even at temperatures around $400^{\circ} \mathrm{C}$.

\section{MATERIALS AND METHODOLOGY}

\subsection{Preparation of the Primary Sols}

Primary sols were prepared by the hydrolysis of a dimethyldiethoxysilane (DEDMS)-triethoxymethylsilane (TEMS) alkoxide mixture, followed by cross linking with zirconium 
propoxide $\left(\mathrm{Zr}(\mathrm{OPr})_{4}\right)$, before the addition of cobalt octanoate.

The basic sol preparation process typically included the following three steps:

1. $x \mathrm{ml}$ of DEDMS was mixed with ethanol (the ethanol volume was usually equal to the combined $($ DEDMS+TEMS) volume $)+$ acidic water $\left(\right.$ aq $\mathrm{HNO}_{3}$ $\mathrm{pH}=1)$. The water content was calculated to be sufficient to hydrolyze the total alkoxide mixture stoichiometrically. Unless stated otherwise, the reaction was allowed to proceed for about $1 \mathrm{~h}$.

2. $y \mathrm{ml}$ of TEMS was added and the mixture was stirred for about $30 \mathrm{~min}$.

3. A $z$-gram amount of zirconium propoxide (containing $23-28 \%$ free alcohol, Fluka chemicals) was added while stirring strongly. Before the $\mathrm{Zr}(\mathrm{OPr})_{4}$ was added it had to be dissolved for about ten times in its volume of dry $\mathrm{CH}_{2} \mathrm{Cl}_{2}$ or $\mathrm{CH}_{2} \mathrm{Cl}-\mathrm{CH}_{2} \mathrm{Cl}$ in order to avoid local zirconium overconcentration, which could lead to an undesirable opalescence due to the quick formation and precipitation of oxopolymers. The most relevant parameter, $\mathrm{B}$, is the $\mathrm{Zr}(\mathrm{OPr})_{4}$ weight relative to the total initial $\mathrm{Si}$ alkoxide weight. So $\mathrm{B}=$ $[\mathrm{z}] /([\mathrm{x}+\mathrm{y}] / 0.9$, where 0.9 is the correction term accounting for the relative densities of the $\mathrm{Si}$ and $\mathrm{Zr}$ alkoxides. This value $\mathrm{B}$ is, however, close to the ratio of solution volumes, since the $\mathrm{Zr}(\mathrm{OPr})_{4}$ solution is about $80 \%$ alkoxide and has a density of 1.05 .

The sols thus obtained were processed into the composite preparation either immediately or after being stored in a freezer for more than 2 weeks.

\subsection{Xerogels Preparation}

Xerogels were prepared from the sols by the following method. Various amounts of cobalt octanoate (cobalt, $8 \%$ in mass) solution in toluene was mixed with the sol to prepare several kinds of composite films, differing by the amount of cobalt relative to the amount of silicon and zirconium. The mixture of the sols and the octanoate solutions yielded homogeneous solutions. Solutions with the following three concentrations, calculated on the basis of the final oxide content in the film, were made:

(I) $\mathrm{Co}_{3} \mathrm{O}_{4} /\left[\mathrm{SiO}_{2}-\mathrm{ZrO}_{2}\right.$ glass $]=10$ mass $\%$ in the final composite film after pyrolysis

(II) $\mathrm{Co}_{3} \mathrm{O}_{4} /\left[\mathrm{SiO}_{2}-\mathrm{ZrO}_{2}\right.$ glass $]=30$ mass $\%$ in the final composite film after pyrolysis

(III) $\mathrm{Co}_{3} \mathrm{O}_{4} /\left[\mathrm{SiO}_{2}-\mathrm{ZrO}_{2}\right.$ glass $]=40$ mass $\%$ in the final composite film after pyrolysis

These solutions were spin-coated on a glass substrate $(18 \times 18 \mathrm{~mm})$ at $2000 \mathrm{rpm}$ for $100 \mathrm{sec}$. After drying for 2 hours at room temperature to give a xerogel, they were heated at $3^{\circ} \mathrm{C} / \mathrm{min}$ to $380^{\circ} \mathrm{C}$ and then pyrolyzed at this temperature for $1 \mathrm{~h}$, leaving a thin hybrid glass-nanoparticle composite film.

\subsection{Glass Characterization}

The composite films were characterized by the following measurements.
Absorption spectra: Shimadzu UV-3100PC double-beam spectrometer

X-ray diffraction patterns: Rigaku RINT2000 X-ray diffractometer

Refractive indices by ellipsometry: Mizojiri DHA-XA2 ellipsometer

Scanning Electron Microscopy (SEM) observation of the film surface (covered with DC-sputtered Au film $10 \mathrm{~nm}$ thick): Hitachi S-5000 scanning electron microscope (acceleration voltage $=20 \mathrm{kV}$ )

Transmission Electron Microscopy (TEM) observation of microstructure of the film: Hitachi H-9000NA transmission electron microscope (operated at $300 \mathrm{kV}$ (acceleration voltage))

\section{RESULTS AND DISCUSSION}

\subsection{Sol Preparation}

The preparation of two- or three-components DEDMSTEMS-ZrOPr 4 basic sols has already been reported [13-17]. Although only a few of the possible procedures and compositions have been tried, the final glass composition seems to be influenced more by the amount of zirconium than by the DEDMS/TEMS proportion. To investigate the glass properties, we made a few test samples without adding Co octanoate.

We tried three zirconium proportions in the sols $-\mathrm{B}=$ $0.05,0.1$ and 0.2 - and in all cases the film obtained after pyrolysis was a transparent and colourless glass. The glasses when $\mathrm{B}=0.1$ or 0.2 were very brittle, so in the rest of the work reported here we used $\mathrm{B}=0.05$ (which corresponds to about $5 \%$ of $\mathrm{ZrO}_{2}$ in the glass).

\subsection{Hybrid Glasses}

\subsubsection{General Features and UV-Visible Spectroscopy}

After pyrolysis, pale brown films were obtained. The films were uniform, hard and not brittle, which is quite surprising since without adding oxide the films were more brittle. The absorption spectra of the films (Fig. 1) had a band below $400 \mathrm{~nm}$ with a shoulder band near either 600 , 660 , or $680 \mathrm{~nm}$ depending on the cobalt oxide content. Like most apparatus, our measurement system is limited at 380 $\mathrm{nm}$, but despite that there is a band around $380 \mathrm{~nm}$ that can be discerned. These bands are characteristics of the spinel type $\mathrm{Co}_{3} \mathrm{O}_{4}$. The absorption bands were blue-shifted from those seen when a pure $\mathrm{Co}_{3} \mathrm{O}_{4}$ film was prepared by simple pyrolysis of Co octanoate, which had absorption bands near $410 \mathrm{~nm}$ and $720 \mathrm{~nm}$ [2] that could respectively be attributed to the $\mathrm{Co}^{3+}$ centre in the octahedral sublattice in the $\mathrm{Co}_{3} \mathrm{O}_{4}$ spinel and to the $\mathrm{Co}^{2+}$ centre in the tetrahedral sublattice in the $\mathrm{Co}_{3} \mathrm{O}_{4}$ spinel. The absorption bands were also blueshifted from those of a pure $\mathrm{Co}_{3} \mathrm{O}_{4}$ film prepared by magnetron RF sputtering $(\approx 410 \mathrm{~nm}$ and $\approx 750 \mathrm{~nm})$ [2]. This blue-shift suggests that the crystal (particle) size of $\mathrm{Co}_{3} \mathrm{O}_{4}$ in this composite film, whatever the oxide content, is smaller than those $(\approx 10 \mathrm{~nm})$ in the pure $\mathrm{Co}_{3} \mathrm{O}_{4}$ films prepared by pyrolysis or by sputtering.

As shown in Fig. (1), the blue shift is related to the oxide content in the films and indicates that the smallest particles 
are found in the most diluted sample and the largest are found in the most concentrated sample. This is what would be expected if the particles had grown by a diffusion-limited aggregation mechanism. Moreover, the fact that the particles in the composite films are smaller accounts for the slower diffusion in the hybrid glass than in the melted octanoate. This interesting feature suggests that the sizes of the particles in the xerogel films can be adjusted by changing the precursor concentration in the sol.

\subsubsection{X-Ray Analysis and Ellipsometry}

A composite film containing $40 \% \mathrm{Co}_{3} \mathrm{O}_{4}$ displayed a weak and broad X-ray diffraction line at $2 \theta=37^{\circ}$ (attributable to the (311) diffraction line of spinel-type $\mathrm{Co}_{3} \mathrm{O}_{4}$ ). It was difficult to obtain low noise X-ray diffraction patterns by our measuring system. The mean crystal size of $\mathrm{Co}_{3} \mathrm{O}_{4}$ particles embedded in the $\mathrm{SiO}_{2}-\mathrm{ZrO}_{2}$ glass film was estimated from the width of the diffraction line to be $\approx 5 \mathrm{~nm}$. The composite films with lower $\mathrm{Co}_{3} \mathrm{O}_{4}$ contents $(10 \%$ and $30 \%$ ) of $\mathrm{Co}_{3} \mathrm{O}_{4}$ showed weaker X-ray diffraction lines at $2 \theta$ $=37^{\circ}$.

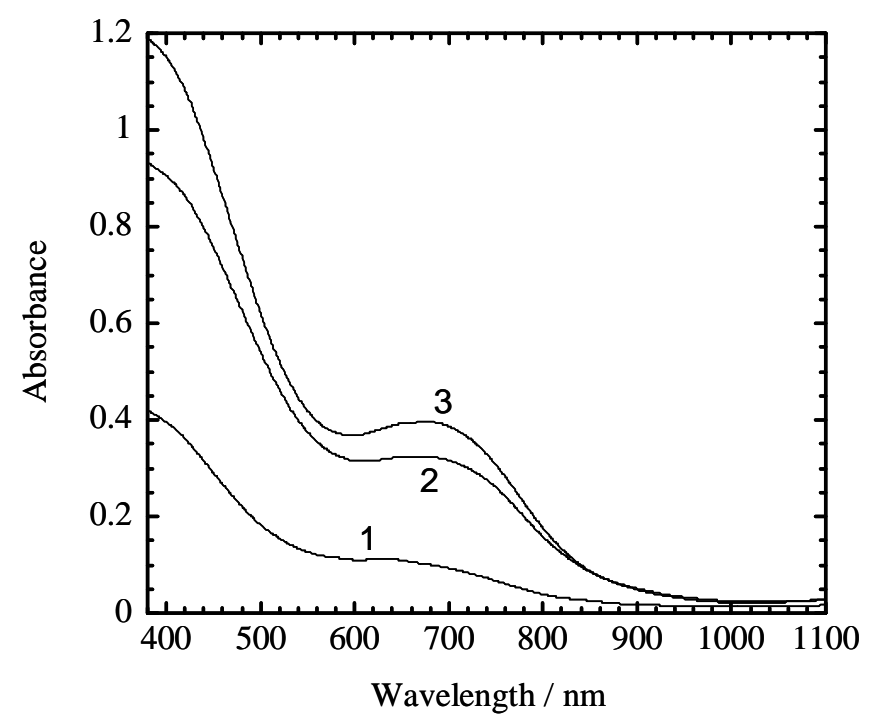

Fig. (1). UV-vis absorbance spectra of composite films containing (1) $10 \%$, (2) $30 \%$, and (3) and $40 \%$ cobalt oxide.

The ellipsometrically measured refractive indexes of the films were compared with values calculated assuming a linear ideal combination of the component indexes according to their relative proportions. For these calculations, the xerogels were assumed to be a blend of zirconia, silica, and the transition metal oxide and the participation of the remaining methyl groups was neglected. The refractive index of pure silica was assumed to be 1.457 , that of pure zirconia was assumed to be 2.1 and that of pure cobalt oxide was assumed to be 1.71 .

The measured and calculated refractive indexes of the three different xerogels, each made from the same basic sol but including various amount of cobalt oxide, are listed in Table 1, where one sees that in each case the calculated index is very close to the measured one and that, as expected, the index of the film increases with the increasing cobalt content.
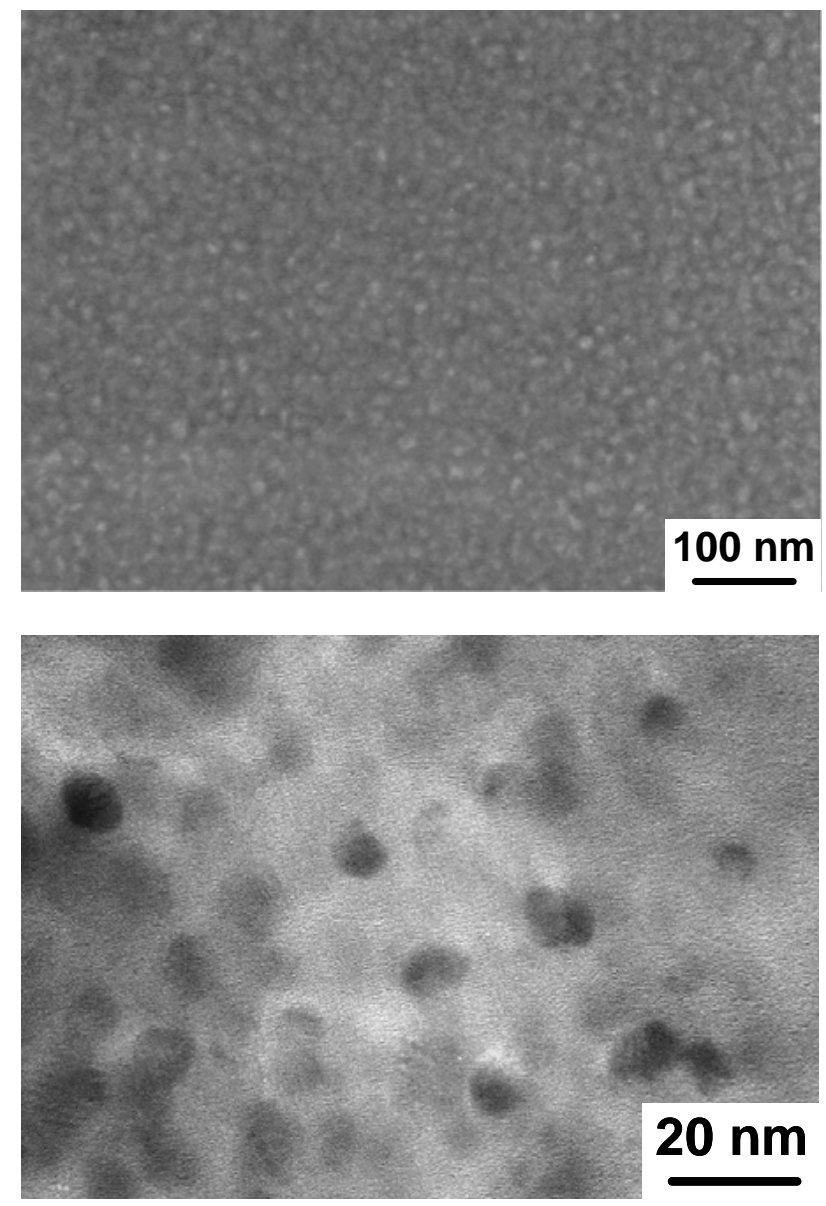

Fig. (2). SEM (top) and TEM (bottom) pictures of a composite film containing $10 \%$ cobalt oxide. The TEM picture shows the nanoparticles clearly.

\subsubsection{Electron Microscopy}

Figs. (2-4) show SEM and TEM pictures of the films. The surface of each film was smooth, uniform and almost free of cracks. In all cases the pictures show that the films contain particles with diameters ranging from $<5 \mathrm{~nm}$ to $\approx 20$ $\mathrm{nm}$. The size of the particles seems to be correlated with the initial cobalt salt proportion, which seems to show that the growth of the oxide particles is a diffusion-limited process. It is likely that the white particles are $\mathrm{ZrO}_{2}$ and the black ones are $\mathrm{Co}_{3} \mathrm{O}_{4}$, the contrast arising from the differences in the respective conductivities of the oxides. This brings further confirmation of the particle size in the films. Concerning the $\mathrm{ZrO}_{2}$ particle size, results obtained in studies of closely related systems [16] show that in hybrid gels made from mixtures of silicon and zirconium alkoxide precursors, the final xerogels contain small zirconia particles with sizes ranging from 20 to $100 \mathrm{~nm}$. In the case we are dealing with, the relatively small initial zirconium content would be responsible for the $\mathrm{ZrO}_{2}$ particles being quite small. We did investigate the relation between the film composition and the size of the nanodomains in detail, but it is clear that the sizes of the particles we obtained are consistent with the smallest reported sizes [16].

The nanosize of all the particles, as well as the fact that the refraction indexes seem well correlated with the relative 

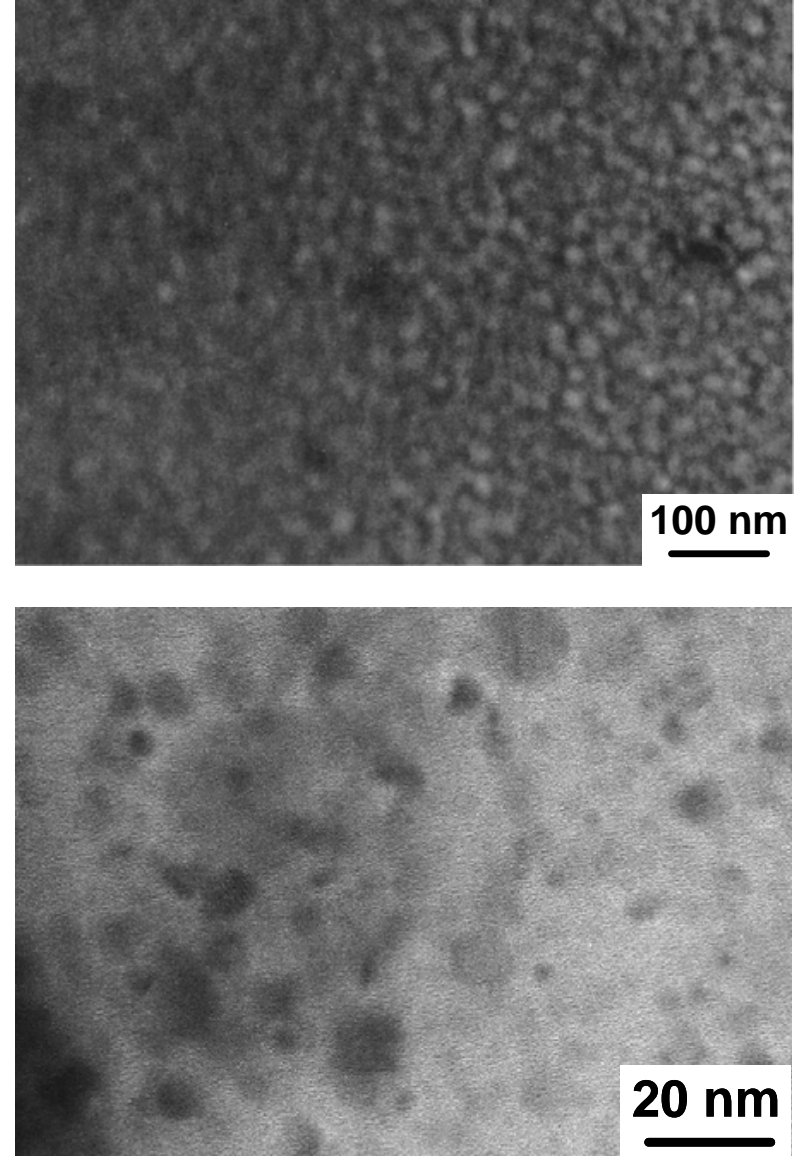

Fig. (3). SEM (top) and TEM (bottom) pictures of a composite film containing $30 \%$ cobalt oxide.

proportion of the oxides tend to show that there is little or no remaining carbon in the films. This is corroborated by the observation that in very similar gels methane evolution began at temperatures over $250^{\circ} \mathrm{C}$ [7] as well as by the fact that the DEDMS/TEMS ratio does not appear to influence the xerogel properties very much.

\section{CONCLUSION}

We have shown in preliminary experiments that combining the sol-gel method and metal salt pyrolysis method is an effective way to prepare uniform and optically high-quality composite films composed of size-regulated $\mathrm{Co}_{3} \mathrm{O}_{4}$ nanoparticles dispersed in organically modified silica glass. The cobalt-content-dependent blue-shift of the absorption band of the $\mathrm{Co}_{3} \mathrm{O}_{4}$ in the composite film and the good agreement between the observed and the expected refractive indexes suggest that the size of the $\mathrm{Co}_{3} \mathrm{O}_{4}$ nanoparticles in the composite film can be controlled precisely.

\section{ACKNOWLDGEMENTS}

The authors thank Ms. Kayo Ikegawa at the National Institute of Advanced Industrial Science and Technology (AIST), Kansai Center, for performing transmission electron microscopy.
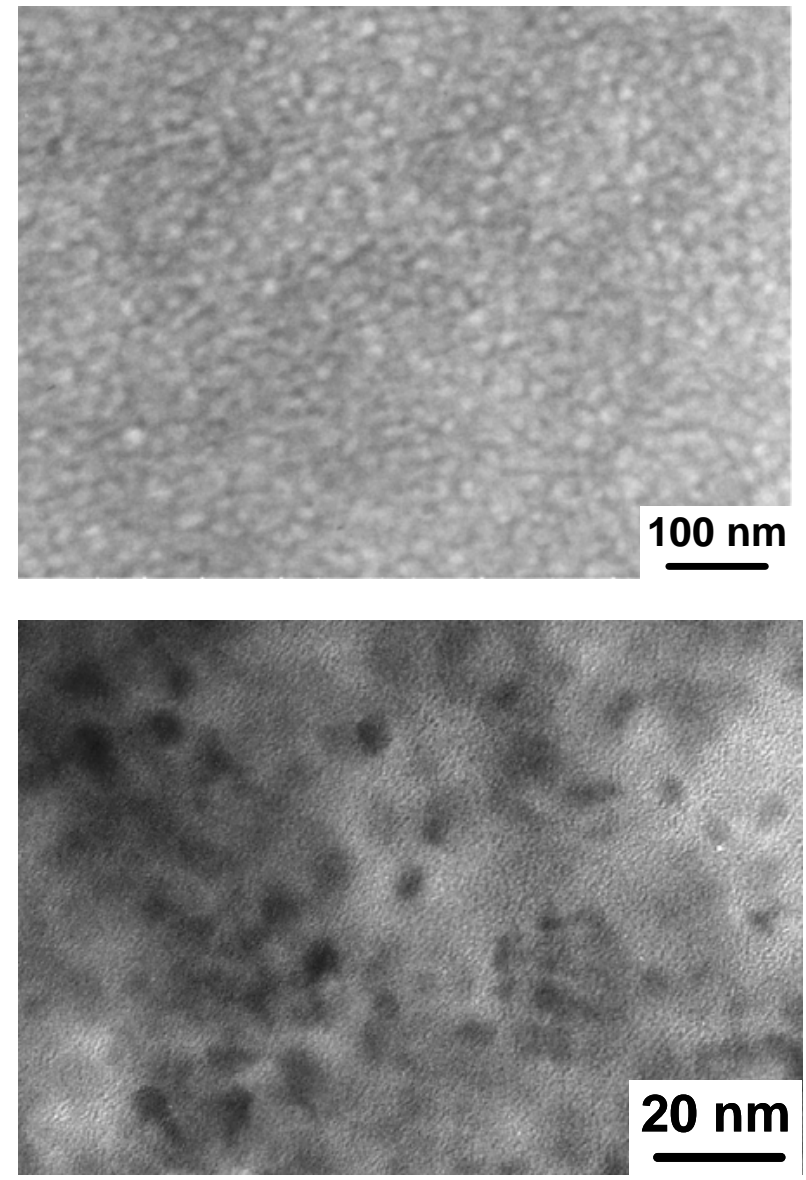

Fig. (4). SEM (top) and TEM (bottom) pictures of a composite film containing $40 \%$ cobalt oxide.

Table 1. Measured and Calculated Refractive Indexes of $\mathrm{Co}_{3} \mathrm{O}_{4}$-Glass Composite Films

\begin{tabular}{|c|c|c|c|}
\hline Cobalt Oxide Content & $\mathbf{1 0 \%}$ & $\mathbf{3 0 \%}$ & $\mathbf{4 0 \%}$ \\
\hline \hline Measured $n$ & 1.516 & 1.565 & 1.575 \\
\hline Calculated $n$ & 1.514 & 1.552 & 1.575 \\
\hline
\end{tabular}

\section{REFERENCES}

[1] Ando M, Kadono K, Haruta M, Sakaguchi T, Miya M. Large thirdorder optical nonlinearities in transition-metal oxides. Nature 1995; 374: 625-7.

[2] Ando M, Kadono K, Kamada K, Ohta K. Third-order nonlinear optical responses of nanoparticulate $\mathrm{Co}_{3} \mathrm{O}_{4}$ films. Thin Solid Films 2004; 446: 271-6 \& Erratum. ibid 2004; 457: 407.

[3] Kobayashi T, Haruta M, Sano H, Delmon B. Optical detection of CO in air through catalytic chromism of metal-oxide thin films. Proceeding of the $3^{\text {rd }}$ International Meeting on Chemical Sensors, Cleveland, $\mathrm{OH}$, USA 1990; pp. 318-21.

[4] Ando M, Kobayashi T, Iijima S, Haruta M. Optical recognition of CO and $\mathrm{H}_{2}$ by use of gas-sensitive Au- $\mathrm{Co}_{3} \mathrm{O}_{4}$ composite films. J Mater Chem 1997; 7: 1779-83. 
[5] Ando M, Kobayashi T, Haruta M. Humidity-sensitive optical absorption of $\mathrm{Co}_{3} \mathrm{O}_{4}$ film. Sens Actuators B 1996; 32: 157-60.

[6] Ando M. Recent advances in optochemical sensors for the detection of $\mathrm{H}_{2}, \mathrm{O}_{2}, \mathrm{O}_{3}, \mathrm{CO}, \mathrm{CO}_{2}$ and $\mathrm{H}_{2} \mathrm{O}$ in air. Trends Anal Chem 2006; 25: 93748 .

[7] Nakai R, Sugii M, Nakao H. Isotopic tracer studies of the ketonic pyrolysis of sodium carboxylates. J Am Chem Soc 1959; 81: 1003-6.

[8] Zou D, Xu C, Luo H, Wang L, Ying T. Synthesis of $\mathrm{Co}_{3} \mathrm{O}_{4}$ nanoparticles via an ionic liquid-assisted methodology at room temperature. Mater Lett 2008; 62: 1976-8.

[9] Esswein A J, McMurdo M J, Ross P N, Bell A T, Don Tilley T. Sizedependent activity of $\mathrm{Co}_{3} \mathrm{O}_{4}$ nanoparticle anodes for alkaline water electrolysis. J Phys Chem C 2009; 113: 15068-72.

[10] Dong Y, He K, Yin L, Zhang A. A facile route to controlled synthesis of $\mathrm{Co}_{3} \mathrm{O}_{4}$ nanoparticles and their environmental catalytic properties. Nanotechnology 2007; 18(Note: 435602): 1-6.

[11] García-Pacheco G, Cabañas-Moreno J G, Yee-Madeira H, CruzGandarilla $\mathrm{F} . \mathrm{Co}_{3} \mathrm{O}_{4}$ nanoparticles produced by mechanochemical reactions. Nanotechnology 2006; 17: 2528-35.
[12] He T, Chen D, Jiao X. Controlled synthesis of $\mathrm{Co}_{3} \mathrm{O}_{4}$ nanoparticles through oriented aggregation. Chem Mater 2004; 16: 737-43.

[13] Livage J, Henry M, Sanchez C. Sol-gel chemistry of transition metal oxides. Prog Solid State Chem 1988; 18: 259-341.

[14] Schaudel B, Guermeur C, Sanchez C, Nakatani K, Delaire J. Spirooxazine- and spiropyran-doped hybrid organic-inorganic matrices with very fast photochromic responses. J Mater Chem 1997; 7: 61-5.

[15] Dirè S, Campostrini R, Ceccato R. Pyrolysis chemistry of sol-gelderived poly(dimethylsiloxane)-zirconia nanocomposites. Influence of zirconium on polymer-to-ceramic conversion. Chem Mater 1998; 10: 268-78.

[16] Roux S, Audebert P, Pagetti J, Roche M. Functionalization of polypyrroles with acids and $\beta$-diketones as complexing groups. Part 2: electrochemical growth of polypyrrole into hybrid zirconium oxopolymer sol-gel coatings. New J Chem 2000; 24: 885-92.

[17] Roux S, Audebert P, Pagetti J, Roche M. Design of a new bilayer polypyrrole-xerogel hybrid coating for corrosion protection. J Mater Chem 2001; 11: 3360-66.

(C) Audebert et al:; Licensee Bentham Open.

This is an open access article licensed under the terms of the Creative Commons Attribution Non-Commercial License (http://creativecommons.org/licenses/ by$\mathrm{nc} / 3.0 /$ ) which permits unrestricted, non-commercial use, distribution and reproduction in any medium, provided the work is properly cited. 